\title{
Trabalho destruído e funcionalização do lazer: possíveis relações em tempos de alta modernidade
}

\author{
Rafael Júnio Andrade* \\ Eveline Torres Pereira** \\ Maria Izabel Vieira Botelho*** \\ Sílvio Ricardo da Silva ${ }^{* * * *}$
}

\begin{abstract}
Resumo: O texto trata das possíveis relações entre o lazer e o trabalho com a formação da Alta Modernidade entendida enquanto um fenômeno histórico - social em uma perspectiva histórico-dialética. O delineamento deste estudo ocorreu através da pesquisa bibliográfica utilizando material público, como revistas, livros, monografias, material iconográfico e percorrendo alguns autores contemporâneos e clássicos. Foi possível concluir que o lazer passou por um processo de instrumentalização no desenvolvimento da Modernidade, vindo apresentar atualmente o papel de revitalização da força de trabalho e de construção de uma disciplina necessária à flexibilização e heterogeinização do trabalho, que caracterizam as sociedades contemporâneas.
\end{abstract}

Palavras-chave: Atividades de lazer. Trabalho. Pós-modernismo.

\section{SOBRE O TRABALHO E A ESFERA PRODUTIVA NO MUNDO CONTEMPORÂNEO}

Historicamente nos estudos do lazer a categoria trabalho representou o principal ponto para as análises. Do final dos anos $90 \mathrm{e}$ início de 2000 surgiram novas problemáticas no cenário intelectual

\footnotetext{
" Licenciado em Educação Física pela Universidade Federal de Viçosa em 2006. Mestrando em Extensão Rural pela Universidade Federal de Viçosa. Viçosa, MG, Brasil. E-mail: rafaefi@yahoo.com.br

"Professora Doutora pela Universidade Gama Filho. Professora Adjunta do Departamento de Educação Física da Universidade Federal de Viçosa. Viçosa, MG, Brasil. E-mail: etorres@ufv.br *** Professora Doutora pela UNESP. Professora adjunta do Departamento de Economia Rural da Universidade Federal de Viçosa. Viçosa, MG, Brasil. E-mail: mbotelho@ufv.br

*** Professor Doutor em Educação Física pela UNICAMP. Professor adjunto da Escola de Educação Física, Fisioterapia e Terapia Ocupacional da Universidade Federal de Minas Gerais. Viçosa, MG, Brasil. E-mail: prof.srs@terra.com.br
} 
e existencial e com esta categoria passaram a conviver outras, também importantes (como a cultura) que ampliaram e aprofundaram os estudos na área.

O trabalho, entretanto representa hoje uma categoria ainda mais complexa frente aos novos processos produtivos e suas relações com a sociedade, o que implica e justifica problematizá-lo de forma a compreendermos algumas facetas do lazer contemporâneo. É esta a proposta deste estudo, que não desconhece nem desvaloriza as outras possibilidades de abordagem do lazer, em especial, suas relações com a cultura, mas que pretende enfocá-lo a partir de suas relações com o trabalho enquanto produto e sujeito da própria cultura contemporânea do sistema de reprodução e produção social.

O homem é um ser social. Essa é uma assertiva bastante óbvia. $\mathrm{O}$ que se deseja dizer com ser social refere-se ao fato de o homem ser um animal que estabelece relações intencionais e racionais com outros homens que vivem na sociedade. Um ser que se sabe histórico e que se organiza através de determinadas relações de forma a poder transformar o mundo e a natureza a seu favor. O trabalho é um processo entre natureza e homem, em que este realiza, regula e controla, mediante sua própria ação, o seu intercambio com a natureza. (MARX, 1982).

Todos os animais e até mesmo os vegetais realizam trabalho. $\mathrm{O}$ trabalho, contudo, no seu sentido propriamente social somente existe para os homens e isso pelo fato de o homem ser o único capaz de elaborar em sua mente o seu trabalho ou sua construção antes de transformá-la em realidade. Os homens se produzem através do trabalho e através dele se relacionam com a natureza e com outros homens. Ele é, portanto, intencional e racional com fins determinados, ou seja, proposital. (MARX, 1982).

O trabalho representa a transformação do mundo, sendo uma das condições que o homem possui de construir e de modificar o mundo natural. Diariamente, através do trabalho, o homem altera o mundo exterior e a si mesmo. Juntamente com a linguagem é possível afirmar que o trabalho é uma das esferas mais significativas quando se trata de saber o que é o ser humano. Apesar de aspectos

Movimento, Porto Alegre, v. 14, n. 01, p. 163-185, janeiro/abril de 2008. 
propriamente ontológicos relacionados ao trabalho serem fundamentais para a compreensão do trabalho humano, busca-se neste artigo, ainda que de maneira germinal, dar ênfase ao trabalho no contexto da sociedade moderna.

Para isso, duas questões iniciais precisam ficar esclarecidas. Uma é sobre o entendimento de industrialismo e outra sobre capitalismo, pois o trabalho se processa dentro destes dois feixes institucionais $^{1}$. Neste ponto, são importantes as contribuições do sociólogo Anthony Guiddens que apesar de se inserir em uma tendência da sociologia, conhecida como sociologia configuracional, apresenta uma substancial contribuição, ao se apropriar de categorias marxistas e durhkhianas, como capitalismo e industrialismo que são tratados enquanto feixes constitutivos da modernidade. Muitas vezes estes dois conceitos são tratados como sinônimos. Outras vezes se toma um enquanto subtipo do outro.

O industrialismo e o capitalismo são na perspectiva de Guiddens (1991) esferas ou feixes característicos das instituições modernas, mas possuem características próprias que estruturam a seu modo, mesmo que interligadas, a vida moderna. De acordo com este autor o industrialismo diz respeito ao uso de fontes inanimadas de energia material para a produção de bens, onde a maquinaria apresenta um papel central no processo de produção. A máquina é um artefato

\footnotetext{
${ }^{1}$ A análise aqui empreendida se baseia, principalmente, nas idéias de Anthony Guiddens em sua obra "Conseqüências da Modernidade"; Ricardo Antunes com suas duas obras "Adeus ao Trabalho? Ensaios sobre a Metamorfose e a Centralidade do Mundo do Trabalho" e "Os Sentidos do Trabalho: Ensaios sobre a afirmação e a negação do trabalho" e Márcio Pochmann com sua obra "O Emprego na Globalização". Guiddens é um dos principais representantes da sociologia configuracional desenvolvida inicialmente por Norbert Elias. Já Ricardo Antunes e Marcio Pochmann apresentam uma tendência marxiana. A utilização destes três autores - e de questões conceituais do próprio Norbert Elias e outros autores com perspectivas diferentestorna-se coerência na medida em que não me aproprio das teorias em si que eles desenvolvem, mas sim de categorias conceituais. Reconheço que existem inúmeras diferenças entre estes autores, contudo opto conscientemente não pelo dialogo entre eles, mas sim pela tentativa de compreensão de um fenômeno, o tempo livre e o lazer, a partir de diferentes contribuições conceituais, dentro da idéia de pensamento complexo, como são desenvolvidos Edgar Morin que reconhece a necessidade da implosão das propostas e conceitos fechados e claros. Esta é a sétima "avenida" que Morin coloca para que possamos superar a fragmentação do saber e realizarmos uma autocrítica da fragmentação e fechamento do conhecimento científico. A aproximação destes autores, assim, fundamenta-se nesta crítica de Morin, contidas no livro Ciência com Consciência de 2005.
}

Movimento, Porto Alegre, v. 14, n. 01, p. 163-185, janeiro/abril de 2008. 
que realiza tarefas ou processos empregando estas fontes de energias enquanto meios de suas operações.

Ele envolve a organização social regularizada da produção no sentido de coordenar a atividade humana, as máquinas e as aplicações e produções de matéria-prima e bens. Ele se materializa tanto em ambiente de baixa tecnologia que lembram os primórdios da revolução industrial, quanto ambientes de alta tecnologia, que envolvem o uso de energia elétrica e redes de microcircuitos eletrônicos. $\mathrm{O}$ industrialismo também atinge tanto o local de trabalho como os transportes, as comunicações e a própria vida cotidiana. (GUIDDENS, 1991; HOBSBAWN, 2002a; 2002b).

É preciso colocar que a principal relação travada entre as pessoas e a natureza na Modernidade a partir do século XIX acontece por meio do industrialismo. Nas culturas pré-modernas as pessoas se relacionavam com a natureza tomando-a como o seu próprio prolongamento, estando suas vidas atadas às disposições do mundo natural. Já com a indústria moderna, que se constrói com a associação entre a ciência e a tecnologia, o mundo da natureza se modifica radicalmente (GUIDDENS, 1991; HOBSBAWN, 2002 a). Neste momento:

\footnotetext{
Nos setores industrializados do globo - e, crescentemente, por toda parte - os seres humanos vivem num ambiente criado, um ambiente de ação que, é claro, é físico, mas não apenas natural. Não somente o ambiente construído das áreas urbanas, mas a maioria das outras paisagens também se torna sujeita à coordenação e controle humanos. (GUIDDENS, 1991, p. 66)
}

Já o capitalismo representa um sistema de produção que se sustenta na relação entre a propriedade privada do capital e o trabalho assalariado sem posse dos meios de produção material, exceto a própria mão-de-obra, como esboço de Marx e Engels (1960). Guiddens (1991) ao se apropriar do conceito marxista de capitalismo, toma-o enquanto um dos feixes que constituem a modernidade e não, como Marx e Engels, o único responsável pela transformação de uma sociedade tradicional ou antiga em uma

Movimento, Porto Alegre, v. 14, n. 01, p. 163-185, janeiro/abril de 2008. 
sociedade moderna. As sociedades modernas são sociedades capitalistas para Guiddens (1991) e, portanto, apresentam as características do sistema capitalista. Uma delas é a constante necessidade de expansão de conjuntos de inovações tecnológicas geradas devido à natureza competitiva e expansionista do capitalismo. Outra questão é uma determinada autonomia e influência da esfera econômica quanto às outras esferas, já que a economia capitalista se fundamenta na posse da propriedade privada dos meios de produção e despossessão dos meios de sobrevivência, vindo transformar, ou seja, institucionalizar o trabalho assalariado em mercadoria (GUIDDENS, 1991; MARX; ENGELS, 1960).

O industrialismo e o capitalismo são, portanto, para Guiddens (1991) esferas institucionalizadas na Modernidade que envolve a todos, estejam conscientes ou não. Estas relações são concretas e atingem todos os horizontes do globo, através dos estados-nação. Os estadosnação modernos possuem um controle coordenado da administração de seus territórios, não alcançado em estados pré-modernos, e é o que permite-lhes o desenvolvimento das atividades industriais e capitalistas. Esse controle administrativo depende do desenvolvimento e aperfeiçoamento das técnicas de vigilância, aqui entendidas como a supervisão e controle das atividades da população nas esferas política e social. Pode ser direta como em prisões e locais de trabalho ${ }^{2}$, por exemplo, e indireta baseada no controle da informação.

O trabalho no mundo moderno, assim, desenvolve-se sob processos de vigilância. Além disso, ele é subdividido em pequenas tarefas a serem executadas por trabalhadores coordenadamente distribuídos no local de trabalho. Outro aspecto ainda mais crucial é o fato de a força de trabalho ser uma mercadoria. Como relataram Marx e Engels (1960) a força de trabalho dos trabalhadores despossuídos dos meios de produção se transformou em mercadoria.

Destacam-se as contribuições do sociólogo brasileiro Ricardo Antunes (1997) que, se apropriando da teoria marxista, coloca que se desenvolveu uma organização do processo produtivo dentro das

${ }^{2} \mathrm{O}$ controle destas esferas foi classicamente tratado por Michel Foucault em seu Vigiar e Punir: Nascimento da Prisão. Tradução: Lígia M. Ponde Vassalo. Vozes. Petrópolis, 1977.

Movimento, Porto Alegre, v. 14, n. 01, p. 163-185, janeiro/abril de 2008. 
indústrias e nas demais esferas do trabalho social com vistas à produção de mais-valia e acumulação de capital e que para isso, atualmente apresenta uma organização da produção e da gestão da mão-de-obra que associa modelos fordistas/tayloristas com técnicas toyotistas ${ }^{3}$. É possível encontrar, argumenta Antunes (1997; 2002), características de ambos os processos convivendo em um mesmo processo produtivo, e até mesmo a predominância de um modelo sobre o outro, uma vez que o importante é garantir a reprodução do capital.

Para Marcio Pochmann (2002), economista brasileiro que trabalha na área de políticas sobre trabalho, esta situação é resultado, muitas vezes, da formação de uma nova empresa baseada na rede eletrônica que procura uma diferenciação dos produtos e serviços oferecidos de forma a estar mais adaptada às variações do mercado e caracterizadas por uma acirrada e desregulada competição intercapitalista. Segundo este autor, há uma transição da produção convencional mecanizada de automação rígida para uma flexível em que predominam os sistemas digitais, os robôs, os computadores associados às máquinas e que buscam uma maior qualidade nos produtos e serviços evitando os estoques e custos financeiros, por meio da maximização da taxa de ocupação e do controle dos meios de produção. $\mathrm{Na}$ alta modernidade:

$[\ldots]$ o novo desenho empresarial se daria a partir do pressuposto da empresa enxuta e competitiva, com ampla integração nas fábricas, maior flexibilidade produtiva e inovadores processos produtivos (just-in-time, sistemas de informação, células de produção e minifábricas). (POCHMANN, 2002, p. 43).

São ainda desencadeadas modificações nas estratégias tomadas para a melhora da competitividade e da produtividade.

\footnotetext{
${ }^{3}$ O fordismo e o taylorismo caracterizam-se, principalmente, pela produção de grandes estoques para amplos mercados, ou seja, é baseado em uma economia de escala. Já o toyotismo, também conhecido como empresa enxuta representa um processo produtivo voltado para pequenos mercados que se formam e se desfazem rapidamente necessitando assim de uma produção rápida de mercadorias. Ele se materializa especialmente pelo just-intime, ou seja, por uma economia de escopo. Ambos condicionam cada qual com suas caracteristicas as relações sociais e a cultura de uma sociedade (ANTUNES, 1997; 2002).

Movimento, Porto Alegre, v. 14, n. 01, p. 163-185, janeiro/abril de 2008.
} 
Desverticalização da produção, diversificação e elevação da qualidade dos produtos, redução dos custos da produção são algumas destas estratégias de competitividade da empresa moderna.

Quanto às estratégias da produtividade, encontram-se a redução dos custos e do tempo morto, melhor aproveitamento das possibilidades da economia de escala e a redução dos estoques (ANTUNES, 1997; POCHMANN, 2002).

Antunes (2002) se aproxima assim das colocações de Pochmann (2002) e argumenta que as novas estratégias empresariais baseadas na competitividade, na produtividade e as novas formas de organização das tarefas, que procuram desenvolver um trabalhador polivalente associado à capacidade de trabalho em grupo, modificam o conteúdo do trabalho. Há para o autor, uma sobreposição de tarefas sobre a responsabilidade de um único trabalhador, o que implica em certo enriquecimento do trabalho devido à transição de postos de trabalho monótonos e repetitivos para postos com maior rotatividade de funções e conteúdo mais complexos. Nesta situação, argumenta Pochmann (2002), primeiramente, não há uma geração em massa ou mesmo significativa deste tipo de emprego, mas sim de ocupações com formas degradantes de trabalho, e em segundo lugar, até mesmo os empregos que tomam esta configuração são marcados por uma exploração mais acentuada dos trabalhadores, especialmente do setor de serviços, que passam a ter suas horas laborais flexibilizadas e estendidas, de forma que todas as suas outras esferas sociais sejam remodeladas.

É neste contexto que se desenvolve uma redução de postos de trabalho na indústria manufatureira e agrícola com a ascensão das ocupações no setor de serviços, composto por uma diversidade acentuada quanto à sua qualidade. Um posto de trabalho no setor terciário pode ser tanto uma consulta particular com um oftalmologista quanto a coleta de papelão nos centros urbanos. Ambos estão em uma mesma categoria de análise, mas são diametralmente opostos, seja quanto à qualificação exigida, seja na perspectiva da garantia das condições de vida do trabalhador e de sua família. Para Antunes $(1997,2002)$ e Pochmann (2002) o inchamento do setor de serviços

Movimento, Porto Alegre, v. 14, n. 01, p. 163-185, janeiro/abril de 2008. 
no mundo do trabalho está associado a uma subproletarização e heterogeinização da força de trabalho, como é apresentado na Tabela $1^{4}$ :

Tabela 1 - Evolução da distribuição dos empregtos por setor econômico em anos e países selecionados (em \%)

\begin{tabular}{|c|c|c|c|c|}
\hline País/Ano & Agropecuária & \multicolumn{2}{|c|}{ Total da indústria } & Total de serviços \\
\hline \multicolumn{5}{|l|}{ Alemanha } \\
\hline Anos 20 & 33,5 & \multicolumn{2}{|c|}{38,9} & 27,6 \\
\hline Anos 70 & 8,7 & \multicolumn{2}{|c|}{47,1} & 44,2 \\
\hline Anos 90 & 4,1 & \multicolumn{2}{|c|}{40,3} & 55,6 \\
\hline \multicolumn{5}{|c|}{ Serviços } \\
\hline Alemanha & Distribuição & \multicolumn{2}{|l|}{ Produção } & Pessoais \\
\hline Anos 20 & 11,9 & 2,1 & 6,0 & 7,7 \\
\hline Anos 70 & 17,9 & 4,5 & 15,7 & 6,1 \\
\hline Anos 90 & 17,7 & 7,3 & 24,3 & 6,3 \\
\hline País/Ano & Agropecuária & \multicolumn{2}{|c|}{ Total da indústria } & Total de serviços \\
\hline \multicolumn{5}{|l|}{ Brasil } \\
\hline Anos 40 & 66,7 & \multicolumn{2}{|c|}{12,8} & 20,5 \\
\hline Anos 70 & 30,8 & \multicolumn{2}{|c|}{27,5} & 41,7 \\
\hline Anos 90 & 20,9 & \multicolumn{2}{|c|}{19,6} & 59,5 \\
\hline \multicolumn{5}{|c|}{ Serviços } \\
\hline Brasil & Distribuição & \multicolumn{2}{|l|}{ Produção } & Pessoais \\
\hline Anos 40 & 8,8 & \multicolumn{2}{|l|}{1,1} & 5,9 \\
\hline Anos 70 & 16,7 & 1,7 & 14,2 & 9,1 \\
\hline Anos 90 & 3,93 & 1,2 & 14,6 & 5,6 \\
\hline País/Ano & Agropecuária & \multicolumn{2}{|c|}{ Total da indústria } & Total de serviços \\
\hline \multicolumn{5}{|l|}{ EUA } \\
\hline Anos 20 & 28,9 & & & 38,2 \\
\hline Anos 70 & 4,6 & & & 62,4 \\
\hline Anos 90 & 3,5 & & & 71,8 \\
\hline
\end{tabular}

Fonte: POCHMANN, Márcio. O Emprego na Globalização. São Paulo: Boitempo, 2002. p. 58.

Está em curso um maciço desenvolvimento de postos de trabalho caracterizados pela precariedade de remuneração, pela desregulamentação das condições de trabalho e das normas legais

${ }^{4}$ Demonstra como a sociedade Moderna toma novas configurações quanto às relações de trabalho. Apesar da importância dos outros setores, o terciário passa a ocupar um grande espaço nas economias dos países gerando diversas conseqüências para o trabalho e o emprego.

Movimento, Porto Alegre, v. 14, n. 01, p. 163-185, janeiro/abril de 2008. 
de trabalho e conseqüente regressão dos direitos sociais, com uma crescente individualização da relação salarial. Como coloca Antunes (1997), “[ . . . ] na França, enquanto houve uma redução de 501 mil empregos por tempo completo, entre 1982 e 1988 deu-se, no mesmo período, o aumento de 111 mil empregos em tempo parcial." (ANTUNES, 1997, p. 44).

Outra característica do trabalho nestes tempos modernos, segundo Antunes $(1997 ; 2002)$ é sua crescente heterogeinização. A classe que vive da venda da sua força de trabalho é incrementada com o maciço contingente feminino em diversas ocupações, além das crianças e dos idosos. Todos são incluídos no processo produtivo, uma vez que há uma progressiva diminuição da renda dos cidadãos e da participação do Estado no papel de redistribuir renda e dar assistência social.

Por fim, é preciso atentar para o fato de que a subproletarização e a heterogeinização, duas características principais das ocupações no setor de serviços, são reflexos da própria taxa de desemprego no mundo, em especial nos países em desenvolvimento, que direciona milhões de pessoas para a realização de formas alternativas de sobrevivência como comprova o Gráfico $1^{5}$ :

Gráfico 1 - Mundo: evolução da taxa de desemprego da força de trabalho (\%), 1975-1999

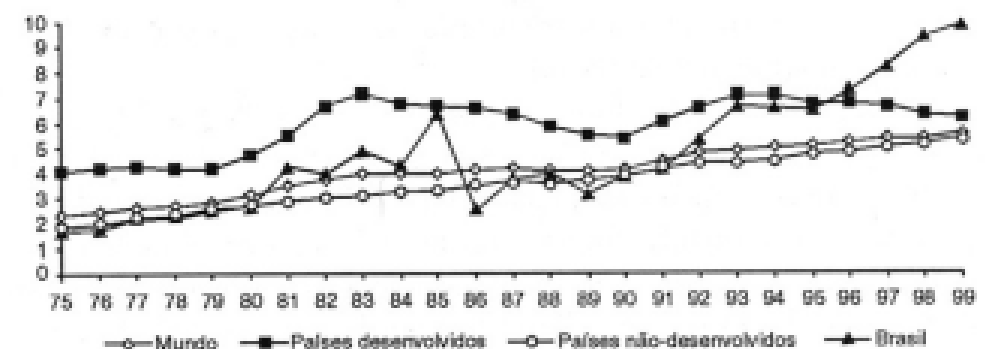

Fonte: POCHMANN, Márcio. O Emprego na Globalização. São Paulo: Boitempo, 2002. p. 86.

${ }^{5}$ Demonstra como o Mundo Moderno se transforma em um local onde as pessoas desenvolvem acentuadamente relações informais de trabalho, reflexo da própria estrutura produtiva moderna, sendo que isso atinge todos os países do mundo.

Movimento, Porto Alegre, v. 14, n. 01, p. 163-185, janeiro/abril de 2008. 
Neste contexto e com estas características quanto à esfera produtiva é preciso pensar e problematizar o tempo referente ao trabalho e ao lazer.

\section{DIVIDINDO O TRABALHO E ABSTRAINDO O TEMPO: INDICAÇÕES DAS CARACTERÍSTICAS DO TRABALHO NA ATUALIDADE}

De acordo com os pesquisadores Nelson C. Marcellino (1996) e Christianne Werneck (2000), uma das discussões mais acirradas dentro do lazer advém da procura pela determinação da sua constituição. Ao ter como uma das suas compreensões aquela em que ele é tomado enquanto tempo disponível e uma atitude tomada pelos sujeitos, diversos autores colocam que o lazer representa uma esfera social que se desenvolveu e tomou a atual identidade, principalmente, com a formação da moderna sociedade urbano industrial.

O lazer passa a ter uma determinada autonomia frente a outras esferas sociais, principalmente, a esfera do trabalho. Antes da formação da sociedade moderna, que tem como um de seus feixes de formação a divisão social do trabalho e a transformação da força de trabalho em mercadoria, essa autonomia ou separação não era concretizada. Na sociedade pré-moderna não existia uma divisão clara entre as atividades produtivas, de sobrevivência e lúdicas. A divisão do trabalho e o uso de fontes inanimadas de energia são as marcas do industrialismo. Com ele o trabalho humano é subdivido em atividades cada vez mais parceladas. O produtor passa a não ter mais controle sobre aquilo que produz e não sabe mais o que produz, para quê e como produz. Ele se aliena do seu produto. Um dos aspectos extremamente importantes quanto à alienação refere-se ao próprio tempo de trabalho que não é mais controlado pela pessoa e se transforma em moeda, como demonstra o historiador inglês $\mathrm{E}$. P. Thompson (1998).

De acordo com Elias (1998) e Guiddens (1991) o tempo se torna uma entidade abstrata, a partir da Modernidade. Para E. Thompson (1998) o tempo com a revolução industrial é a constituição

Movimento, Porto Alegre, v. 14, n. 01, p. 163-185, janeiro/abril de 2008. 
de um mercado auto-regulável. Elias (1998) e Guiddens (1991) ao realizarem uma comparação entre as sociedades históricas colocam que se nas sociedades pré-modernas o tempo era na maioria das vezes imprevisto, sendo marcado em função de diversos marcadores espaciais, na Modernidade isso não acontece mais. O tempo foi esvaziado e com a ação dos relógios mecânicos foi uniformizado. As pessoas seguem determinados horários para realizarem suas atividades em comparação a outros horários e espaços. Para os autores é possível visualizar o caráter dinâmico e abstrato do tempo criado pela Modernidade. O tempo agora é vivenciado sobre estas bases. Ele permite à sociedade realizar atividades diversas em um mesmo período, pois é "contado" sobre um intervalo abstrato de comparação.

Tanto Elias (1998) quanto Guiddens (1991) argumentam que esta forma completamente moderna de tempo possibilita à sociedade controlar de forma mais eficiente a esfera material que garante sua sobrevivência, ou seja, o trabalho. Octavio Ianni (2000), sociólogo brasileiro, com uma tendência marxista, argumenta - diferentemente de Elias (1998) e Guiddens (1991) que brilhantemente compreendem este processo, mas vêem o mesmo enquanto parte de um movimento inevitável e integrado-, que ao se conseguir fazer com que o tempo do trabalho possa ser "contabilizado", "aplicado" e com isso tornarse possível controlar, com uma eficiência não antes atingida, o processo de trabalho e produção das condições materiais para a existência humana, o capitalismo e o industrialismo passam a ter domínio, também sobre a vida dos homens e da sociedade (IANNI 1997; 2000). Para este autor todas as outras esferas da vida social, como a religião, a educação, a própria cultura são vividos com referência ao trabalho. Isso não se deu por acaso. O trabalho organizado por meio dos processos industriais e capitalistas de produção demonstrou uma força descomunal a todos. Mostrou o que Marx e Engels enfatizaram no século XIX, de como é possível criar vida humana e realizar as construções, modificações, controlar o mundo de uma forma somente imaginada (MARX, 1982; MARX; ENGELS, 1960).

Movimento, Porto Alegre, v. 14, n. 01, p. 163-185, janeiro/abril de 2008. 
Este tempo de trabalho, contudo, também apresentava e apresenta seu lado obscuro. Para Nietzche (1983, p. 386):

De fato todo grande crescimento traz consigo tam-
bém um descomunal esboroamento e perecimen-
to, o sofrer, os sintomas do declínio fazem parte
dos tempos de descomunal avanço; cada fecundo e
potente movimento da humanidade criou ao mes-
mo tempo um movimento niilista.

Ao se tomar o trabalho moderno como produto da dupla Revolução ${ }^{6}$ é possível perceber que esse perecimento - parte do niilismo - é representado pelo aspecto alienante que o trabalho tomou e também, pela sua "autonomia", pelo menos até o momento definitivo, das outras esferas sociais? ${ }^{7}$. Existe agora um tempo destinado ao trabalho assalariado. Um tempo único a ser seguido pela maioria das pessoas, pois a sociedade passa a se formar na divisão entre aqueles que controlam os meios de produção e aqueles que somente detêm sua força de trabalho (MARX, 1982; MARX; ENGELS, 1960).

Este tempo de trabalho, por sua vez, conseguiu demonstrar que o homem poderia finalmente conseguir o paraíso na terra diminuindo sua dependência com relação à natureza e podendo usufruir da satisfação de todas as suas necessidades. A sociedade, contudo, estando dividida entre grupos antagônicos não possibilita a distribuição eqüitativa de suas produções ${ }^{8}$. Por outro lado, com a determinação do tempo de trabalho e seu caráter de obrigação e expropriação se constituíram outros intervalos de tempo. Todos se construindo, principalmente, a partir da referência ao tempo de trabalho.

\footnotetext{
${ }^{6}$ A dupla revolução foi a Revolução industrial (caracteristicamente inglesa) e a revolução política (francesa).

${ }_{7}$ Politicamente falando o Niilismo concebe que somente pode existir progresso com a destruição completa daquilo que existe sociamente e foi isso que a dupla Revolução fez: destruiu a camada de gelo que ao mesmo tempo protegia e limitava as sociedades antigas à sua própria existência de forma a implementar uma nova ordem, não apenas econômica, política, social e cultural, mas também conseqüemente ética e estética, na qual não existe estabilidade, onde tudo que é sólido se desmancha no ar, como argumenta Marshall Berman (1985; 2003) e Marx; Engels (1960).

${ }^{8} \mathrm{Na}$ teoria clássica marxista seriam respectivamente: os detentores dos meios de produção e aqueles que possuem apenas a sua força de trabalho.
}

Movimento, Porto Alegre, v. 14, n. 01, p. 163-185, janeiro/abril de 2008. 
O tempo de lazer foi uma esfera construída prioritariamente com base na oposição do próprio tempo destinado ao trabalho. O tempo para não se trabalhar, disponível para se realizar outras atividades que não a produção de bens e serviços para outrem. Um tempo que possa ser utilizado, preenchido de acordo com os interesses e necessidades dos próprios indivíduos (MARCELLINO, 1995; 1996; WERNECK, 2000).

Este tempo foi constituído, portanto, dentro da própria modernidade e precisa ser entendido por dentro de suas estruturas.

Enquanto atravessada institucionalmente pelo capitalismo a modernidade é marcada por uma constante efervescência, por uma contínua necessidade de modificação e superação de formas de se relacionar com o mundo e os homens. Assim o tempo disponível e o próprio tempo do trabalho são continuamente modificados de forma a permitir a própria expansão do capital $^{9}$ (MARX, 1982; MARX; ENGELS, 1960).

O tempo atual não é um tempo mecânico, marcado por horas e minutos, mas um tempo eletrônico controlado a partir de intervalos cada vez menores: segundos, milésimos. Este tempo dá ao trabalho imperativos ainda mais acentuados de produtividade e competitividade. O tempo de trabalho é controlado até as mínimas parcelas e com ele as próprias pessoas. É preciso produzir cada vez mais rápido para os mercados, também, cada vez mais volúveis. $\mathrm{O}$ trabalhador é emaranhado em técnicas de vigilância ainda mais eficientes e sutis. Um esquadrinhamento completo de todo o tempo é desenhado para que nada se perca no processo produtivo

O tempo é também marcado por períodos flexíveis de trabalho na indústria capitalista moderna. É uma nova indústria que combina técnicas tayloristas/fordistas com técnicas toyotistas. O trabalhador agora não tem um tempo de trabalho fixado a ser seguido

\footnotetext{
${ }^{9}$ A necessidade de expansão contínua é uma inerência do modo de produção de mercadorias, uma vez que o capital tende a uma taxa decrescente de valorização, ou seja, produção de mais valia, fazendo-se obrigatório se aprimorar as modalidades de extração da própria maisvalia, seja intensivamente ou extensivamente, ou como acontece hoje combinando estas duas formas.
}

Movimento, Porto Alegre, v. 14, n. 01, p. 163-185, janeiro/abril de 2008. 
durante toda a sua vida. Não significa que todos os trabalhadores somente trabalhem de forma flexível. Uma característica dos tempos de alta modernidade é a convivência de diversas formas de uma determinada atividade (ANTUNES, 1997; 2002; GUIDDENS, 1991; POCHMANN, 2002).

Coexistem, dessa forma, variadas combinações de técnicas de produção capitalista. Um fato, contudo, é comum neste quadro e ele diz respeito ao crescente aumento da participação do setor de serviços dentro dos processos sociais de produção (Tabela 1). Associado a isso está a crescente precariedade e subproletarização do trabalho em todas as esferas (Gráfico 1).

\section{ConcLUSÃo: FLEXIONAR O TRABALHO E FUNCIONALIZAR O LAZER}

As características anteriormente apontadas são efeitos de uma problemática maior da sociedade moderna. É o problema do desemprego estrutural, ou seja, o desemprego em massa que atinge a todos os extratos da população. Além da geração de empregos no mundo moderno ser em escala insuficiente, estes empregos são, na sua maioria, temporários e de baixa qualificação. O ambiente moderno de trabalho flexibilizado acaba por influenciar o próprio lazer. Não significa que o determine, mas condiciona algumas das características que ele passa a ter.

$\mathrm{Na}$ sociedade moderna o lazer passa a ter um conteúdo funcionalista na medida em que o trabalho não possibilita formas satisfatórias de transformar as pessoas. A alienação no trabalho reflete-se no próprio lazer. Apesar da relação não ser direta, é possível inferir que o lazer é desenvolvido pelas pessoas enquanto compensação daquilo que o trabalho não proporciona. $E$ isso não reflete somente nas pessoas comuns, que em muitas das vezes conseguem re-significar esta situação de acordo com suas possibilidades, mas principalmente com as próprias autoridades públicas responsáveis por uma política de lazer que o concebem e se relacionam com o mesmo dentro desse paradigma (MARCELLINO, 1995; 1996).

Movimento, Porto Alegre, v. 14, n. 01, p. 163-185, janeiro/abril de 2008. 
Os órgãos municipais, estaduais e o Estado nacional - que implementaram a política do Welfare State, após Segunda Guerra e foram também aqueles que primeiro o abandonaram a partir das crises de 1970, passam a visualizar o lazer somente enquanto um elemento compensatório das relações de trabalho. Inúmeras vezes ele é associado a campanhas educativas que visam "desresponsabilizar" o próprio sistema social quanto à falta de compromisso com direitos civis básicos, como saúde, por exemplo: (ANTUNES, 2002; MARCELLINO, 1996; MASCARENHAS, 2003).

É claro que o lazer apresenta um conteúdo educativo muito importante. É preciso sim utilizá-lo enquanto veiculo de educação. É preciso questionar, entretanto, sua utilização massiva como elemento amortecedor das contradições sociais e, principalmente, moralizador das condições individuais de existência. O lazer é colocado pelos órgãos públicos como uma recompensa pelas horas destinadas ao trabalho desgastante. Assim ele apresenta segundo Mascarenhas $(2003 ; 2005)$ uma conotação funcionalista. O tempo de lazer na maioria das vezes é disseminado enquanto um momento para a recuperação das forças necessárias para a realização do trabalho. Outro aspecto intrinsecamente ligado a esta perspectiva é a disseminação do lazer enquanto tempo importantíssimo para a formação profissional. Novamente é preciso colocar que a educação pelo lazer representa uma prática importante e necessária para a sociedade. (MARCELLINO,1990; 1996). Admitir isso significa ter consciência das possibilidades que o lazer possui, mas não quer dizer, ser mais adequado a instrumentalização em si do mesmo. (reformular esta frase)

No contexto atual, o que se verifica de acordo com Antunes (1997; 2002), Ianni (2000) e Pochmann (2002) é a valorização crescente da utilização do lazer enquanto veículo de aprimoramento dos sujeitos para a realização de suas atividades laborais. O lazer se torna uma extensão da formação continuada para o próprio trabalho. Um grande problema desta tendência é que as pessoas acabam impossibilitadas de vivenciar outras esferas de lazer em detrimento da segurança no seu trabalho. Com isso, mesmo que as pessoas tenham prazer em atividades estreitamente ligadas às suas

Movimento, Porto Alegre, v. 14, n. 01, p. 163-185, janeiro/abril de 2008. 
atividades laborais, desenvolve-se uma relação de afunilamento das suas experiências e saberes. Esse é um reflexo do lazer na Alta Modernidade: sua ocorrência enquanto elemento funcional e utilitário. Objetiva-se que as pessoas interiorizem uma moral de serem responsáveis por sua situação social e cultural e, principalmente, pela sua permanência e melhora dentro do mundo do trabalho. Diante de uma lógica de subproletarização, de flexibilização das relações de trabalho os sujeitos não possuem alternativa exceto a própria instrumentalização do seu lazer. Como salienta Victor Andrade de Melo e Edmundo Alves Júnior (2003) ocorre uma falsa associação da ludicidade no trabalho, que na verdade esconde a intensificação da exploração, como ocorre com empregados de empresas de serviços informacionais, ou mesmo vendedores que passam a ter acesso a diversos elementos ditos lúdicos, como um ambiente com música, maior conforto quanto ao layout, mas, passam a ter que trabalhar um maior número de horas de acordo com as necessidades da empresa e do mercado.

Os trabalhadores comuns, em sua maioria aqueles que detêm um poder econômico bastante inferior, vivem outra lógica. Para aqueles que conseguem ter mais acesso a melhores condições de saúde, educação, habitação, e principalmente econômicas, desenvolve-se um processo febril de consumo de atividades e serviços de lazer, como viagens, compras em shoppings, academias. Como bem coloca o sociólogo argentino Néstor Garcia Canclini (2003) a respeito das culturas latino-americanas, o mundo público passa a ser reorganizado pelo mercado enquanto palco de consumo e de dramatização no qual as pessoas se encontram permanentemente apressadas para cumprirem suas obrigações sejam elas profissionais ou pessoais e para desfrutar formas de diversão programadas na maioria das vezes de acordo com a renda econômica.

O lazer passa a significar possibilidade de consumo dos mais variados bens e serviços. É preciso caminhar pelo shopping e comprar um tênis, uma blusa, mesmo não se desejando inicialmente comprar. Nenhum passeio se torna completo se não envolver o consumo, o gasto com produtos e serviços. Tem-se a sensação de viver um “Admirável Mundo do Lazer".

Movimento, Porto Alegre, v. 14, n. 01, p. 163-185, janeiro/abril de 2008. 
É estranho, [... ], pensar que mesmo na época de Nosso Ford a maioria dos jogos limitava-se a uma ou duas bolas e alguns bastões e por vezes em pedaço de rede. Imaginem a tolice de deixar as pessoas disputarem jogos complicados que em nada contribuam para o aumento do consumo. É uma insensatez. Hoje os dirigentes não aprovariam um jogo que não demonstrasse exigir um mínimo de equipamento equivalente ao mais complicado dos jogos existentes. (HUXLEY, 1968, p. 56).

Para esta parcela da população composta principalmente pela classe média, o lazer toma a conotação de um tipo muito interessante de trabalho. Um trabalho de compras e gastos. Assim como no trabalho de uma forma geral os sujeitos desenvolvem rituais desempenhando atividades repetitivas, no lazer as pessoas precisam caminhar em uma direção semelhante. É preciso adquirir alguma mercadoria no tempo de lazer, caso contrário, não se terá realmente vivenciado-o.

É importante perceber que esta situação é vivida por uma minúscula parcela da população brasileira, especialmente as camadas alta e média, entretanto são os desejos, valores e saberes destas classes que configuram a realidade ideológica do país. São estas representações de desejos e valores que são colocadas como parte intrínseca da identidade brasileira devendo grande parte da nação, ou quase todos os outros grupos caracterizados por uma baixa renda, se adaptar a esta situação para se sentirem brasileiros.

O lazer toma neste contexto um valor de mercadoria veiculando produtos e serviços a serem consumidos enquanto garantia da própria felicidade. Ser moderno implica em ser feliz e para que estas duas condições sejam alcançadas é preciso ter um padrão crescente de consumo, como argumenta Jean Baudrillard (1995), ao visualizar os lazeres enquanto signos do consumismo. Valquiria Padilha (2003) ao analisar o crescimento dos Shoppings Centers no Brasil, verifica um avanço desta sociedade na qual o lazer é reificado e se transforma em um dos principais signos de consumo. Impera a melodia do consumo como mostra a canção abaixo:

Movimento, Porto Alegre, v. 14, n. 01, p. 163-185, janeiro/abril de 2008. 
Compre/ Veja e /Assine / Ligue já/ Leve dois, pague três/ Adquira/ O imperativo reina/ Na telinha da televisão/ Você com esse bundão/ Sentadinho no sofá/ Da sala de estar. ${ }^{10}$

O lazer nesta situação se transforma em um importante elemento na lógica da produção do sistema de mercadorias. É preciso que sejam acirrados, novos e irresistíveis desejos nos sujeitos. Todas as classes, gêneros, idades, raças e tribos são convocadas ao reino da felicidade.

Segundo Antunes (1997), dissolve-se a esperando e a vontade política de buscar (verificar, sem sentido) formas alternativas e mais justas nas relações de trabalho, pois para os trabalhadores, seja em uma sociedade capitalista ou socialista, todos terão que trabalhar. Mascara-se, contudo, a situação de extrema injustiça e expropriação que marcam as relações atuais de trabalho. Antunes (1997) e Ianni (2000) argumentm que, com este movimento, há uma construção ideal de fim da história, fim da geografia. Somente existe a relação capitalista de produção entre os homens, sendo, a única correta e, também, a forma final. Isso não significa que outras parcelas da população não sejam impulsionadas para uma moral do trabalho de consumo. É, contudo, está parcela da sociedade formada pelas classes média e alta que representam a grande mola propulsora desta lógica, uma vez que sua própria concepção de mundo é complementar a esta situação. Já para os segmentos mais baixos da população, segundo este autor, ocorre uma crescente improvisação de espaços e atividades de lazer. Isso por um lado representa um movimento positivo na medida em que permite explorar e desenvolver a própria criatividade e organização, como por exemplo, entre grupos de crianças de um 'morro' que se organizam para limpar um terreno e construir um campinho de futebol.

Para Mascarenhas $(2003 ; 2005)$ a situação demonstra falta de condições de acesso a espaços e atividades de lazer associado à falta de compromisso e responsabilidade do poder público. Esta

${ }^{10}$ Canção: Imperativo. "Ta Na Boa." Tianastácia. Emi.-1999.

Movimento, Porto Alegre, v. 14, n. 01, p. 163-185, janeiro/abril de 2008. 
parcela da população que é composta pelas famílias de trabalhadores do setor informal da economia, e principalmente, aqueles que possuem ocupações com uma renda reduzida que impede o consumo de bens e serviços são tomados como um mal inevitável da sociedade. O lazer para esses grupos acaba por ser confundido muitas vezes com o ócio, que representa uma das possibilidades a ser vivenciada dentro do quadro das escolhas e do tempo disponível dos sujeitos. Ele não é o lazer em si, pois existem alternativas diversas, dentro de um conjunto de atividades existentes.

A questão é que grande parte da população de diversos países desenvolve ou atividades em setores informais da economia ou estão em ocupações marcadas pelo padrão de acumulação flexível. Estão, deste modo, desenvolvendo atividades em que não existe um padrão de horários fixos a serem seguidos nem mesmo condições legais que protejam os trabalhadores da irracionalidade do mercado. Existe uma rotina que varia em função das necessidades da produção, podendo os sujeitos trabalharem até dez horas diárias todos os dias da semana e terem somente um dia de folga na semana seguinte ou terem até mesmo uma semana de descanso caso a produção exija (ANTUNES, 1997; 2002; MASCARENHAS, 2005; POCHMANN, 2002)

A sociedade está, pois, organizada por feixes das mais diversas formas de relações de trabalho. Estas relações, todavia, são compostas por elementos invariáveis, como a existência de sujeitos que precisam vender sua força trabalho por um salário. A maior parte destes sujeitos se encontram, em tempos de alta modernidade, desocupados - ocupados. Com isso se pretende dizer que os trabalhadores frente às novas tecnológicas de produção representadas especialmente pela indústria toyotista, dispõem de um tempo "liberado" do trabalho bastante significativo. Não é, contudo, uma liberação positiva resultante da diminuição da jornada de trabalho, vindo assegurar os direitos dos trabalhadores e proporcionar o dito 'paraíso' na Terra. Na verdade é um tempo de ociosidade, ou seja, um tempo em que os sujeitos estão à procura de trabalho, mas não conseguem encontrá-lo (ANTUNES, 1997; 2002; MARCELLINO, 1996).

Movimento, Porto Alegre, v. 14, n. 01, p. 163-185, janeiro/abril de 2008. 
As classes sociais formadas principalmente pela população de baixa renda, com baixa qualificação profissional e educacional e que desenvolvem atividades com baixa remuneração se encontram em uma situação paradoxal: têm mais tempo para desfrutar com a família, amigos e para realizar outras atividades. Estão, entretanto, à procura de empregos, pois lhes fora disponibilizado o tempo em troca de não terem mais uma ocupação, uma renda mensal, mesmo que mínima, mas garantida (MARCELLINO, 1996).

$\mathrm{Na}$ Alta Modernidade o ócio enquanto um conteúdo do lazer torna-se um elemento de difícil determinação. Ele não representa somente momentos vividos fora da esfera do trabalho e com um alto grau de escolha dos sujeitos. Com o desmanche constante de tudo que existe no mundo em especial da garantia de um posto no trabalho fica o próprio lazer esfumaçante. Ele se torna uma esfera fragmentada da vida social das pessoas, podendo acontecer em diversos locais e também, não vir a ocorrer permanecendo condicionado, como diria Orwell (1997) pelo seu Grande Irmão, que não é neste caso principalmente político, mas sim econômico, ou seja, o mercado. Com isso é possível visualizar que o lazer no ambiente moderno permanece condicionado pelas condições de classe, ou seja, pelas possibilidades e relações que os sujeitos estabelecem com e no trabalho e como diria o poeta: "Eu vejo o futuro repetir o passado, eu vejo um museu de grandes novidades, o tempo não pára, não pára, não, não pára." (CAZUZA, 1998) ${ }^{11}$

E assim seguindo as trilhas abertas por Lafargue (2000) continuemos a trabalhar mais e mais para que possamos consumir mais e mais, e no final não consigamos deixar de, ingenuamente, nos divertir trabalhando e comprando.

${ }^{11}$ Canção O tempo não pára. CD CAZUZA. Coleção Millenium. Polygram. 1998.

Movimento, Porto Alegre, v. 14, n. 01, p. 163-185, janeiro/abril de 2008. 


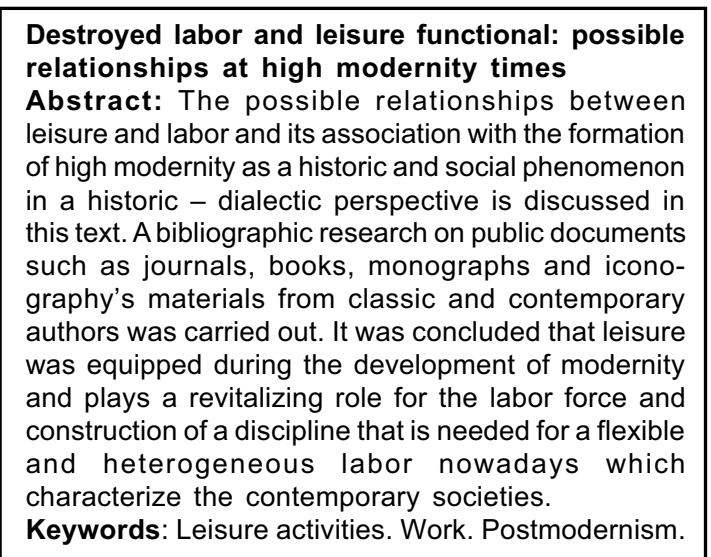
Trabajo destruído y funcionalización del ocio:
posibles relaciones en tiempos de alta modernidad
Resumen: El texto trata de las posibles relaciones
entre el ocio y el trabajo con la formación de la alta
Modernidad comprendida en cuanto un fenómeno
histórico-social en una perspectiva histórico-
dialéctica. El delineamiento de este estudio ocorrió a
través de la investigación bibliográfica utilizando
material público como revistas, libros, monografías,
material iconográfico e recurriendo a algunos auto-
res contemporáneos y clásicos. Fue posible con-
cluir con este estudio que el ocio pasó por un proceso
de instrumentalización en el desarrollo de la
Modernidad, venindo presentar actualmente el papel
de revitalización de la fuerza de trabajo y de la
construcción de una disciplina necesaria a la
flexibilización y heterogenización del trabajo, que
caracterizan las sociedades contemporáneas.
Palabras-clave: Actividades recreativas. Trabajo.
Postmodernismo

\section{REFERÊNCIAS}

ANTUNES, Ricardo L. C. Adeus ao trabalho? Ensaios sobre a metamorfose e a centralidade do mundo do trabalho. Campinas: São Paulo: Cortez, 1997.

Os Sentidos do trabalho: ensaios sobre a afirmação e a negação do trabalho. São Paulo: Boitempo, 2002.

Movimento, Porto Alegre, v. 14, n. 01, p. 163-185, janeiro/abril de 2008. 
BAUDRILLARD, Jean. Sociedade de Consumo. Tradução de Artur Morão. Lisboa: Edições 70, 1995.

CANCLINI, Néstor G. Culturas híbridas: estratégias para entrar e sair da Modernidade. Tradução Ana Regina Lessa e Heloíza Pizza Cintrão. 4. ed. São Paulo: EDUSP, 2003

CAZUZA; BRANDÃO, Arnaldo. O tempo não pára. São Paulo: Polygram, 1989. $1 \mathrm{CD}$. (Coleção Millenium).

ELIAS, Norbert. Sobre o tempo. Tradução Vera Ribeiro. Rio de Janeiro: Jorge Zahar, 1998

GUIDDENS, Anthony. As conseqüências da Modernidade. Tradução: Paul Fuker. São Paulo: UNESP, 1991.

HOBSBAWN, Eric J. A Era das revoluções: Europa 1789-1848. Tradução: Maria Tereza Lopes Teixeira e Marcos Penchel. 16. ed. Rio de Janeiro: Paz e Terra, 2002a.

A era do capital: 1848-1871. Tradução: Luciano Costa Neto. 9. ed. Rio de Janeiro: Paz e Terra, 2002b.

HUXLEY, Aldous. Admirável mundo novo. Tradução: Felisberto Alburquerque. 4. ed. Rio de Janeiro: DINAL, 1968.

IANNI, Octávio. Enigmas da modernidade-mundo. Rio de Janeiro: Civilização Brasileira, 2000

Teorias da globalização. Rio de Janeiro: Civilização Brasileira, 1997.

LAFARGUE, Paul. O Direito à preguiça. 2. ed. São Paulo: Hucitec; UNESP, 2000.

MARCELLINO, Nelson Carvalho. Lazer e educação. Campinas: Papirus, 1990 1996

Estudos do lazer: uma introdução. São Paulo: Autores Associados

Lazer e humanização. Campinas: Papirus, 1995.

MARX, Karl. O capital: crítica da economia política. O processo de produção do capital. Tradução de Reginaldo Sant'Anna. 8. ed. São Paulo: Difel, 1982. V. 1.

MARX, K.; ENGELS, F. Manifesto do Partido Comunista. 4. ed. Rio de Janeiro: Vitória, 1960

MASCARENHAS, Fernando. Entre o ócio e o negócio: teses acerca da anatomia do Lazer. 2005. Tese (doutorado) - Faculdade de Educação Física, Universidade Estadual de Campinas. Campinas, SP, 2005. Disponível em: <www.boletimef.org>. Acesso em: 20 fev. de 2006.

Movimento, Porto Alegre, v. 14, n. 01, p. 163-185, janeiro/abril de 2008. 
O pedaço sitiado: Cidade, cultura e lazer em tempos de globalização. Revista Brasileira de Ciências do Esporte, Campinas, v. 24. n. 3, p. 121-143, maio 2003.

MELO, Victor Andrade de; ALVES JÚNIOR, Edmundo de D. Introdução ao lazer. Barueri: Manople, 2003.

NIETZCHE, F. W. Obras incompletas. Seleção de Gérard Lebrun. Tradução e notas de Rubens Rodrigues Torres Filho. São Paulo: Abril Cultural, 1983. (Os Pensadores).

ORWELL, George. 1984. Tradução: Wilson Velloso. 10. ed. São Paulo: Companhia Editora Nacional, 1997.

PADILHA, Valquiria. Shopping center: a catedral das mercadorias e do lazer reificado. 2003. Tese (doutorado) - Departamento de Sociologia do Instituto de Filosofia e Ciências Humanas, Universidade de Campinas. Campinas, 2003.

POCHMANN, Márcio. O Emprego na globalização. São Paulo. Boitempo, 2002.

THOMPSON, E P. Costumes em comum. Tradução: Rosaura Eichemberg. São Paulo: Companhia das Letras, 1998.

WERNECK, Christianne. Lazer, trabalho e educação: relações históricas, questões contemporâneas. Belo Horizonte: UFMG, 2000.

Movimento, Porto Alegre, v. 14, n. 01, p. 163-185, janeiro/abril de 2008. 